\title{
Resumen de Tesis: La práctica alfarera durante el primer milenio de la Era en El Sunchal, Anfama (Dto. Tafí Viejo, Tucumán, Rep. Argentina). Trayectorias de vida, cadenas operativas y ¿tradición? ${ }^{1}$
}

\author{
Francisco Franco \\ (Instituto de Estudios Históricos- Universidad Nacional de Córdoba) \\ franfranco@unc.edu.ar
}

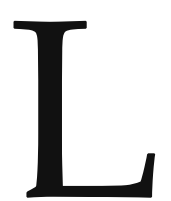

as sociedades que habitaron el Noroeste Argentino hacia 2000 AP experimentaron una serie de transformaciones sustanciales, que implicaron la incorporación de cultivos, pastoreo de camélidos, alfarería y, fundamentalmente, el establecimiento de las primeras aldeas permanentes en la región. Ese modo de vida aldeano, hacia los años 1100 a 1000 AP entra en un proceso de reconfiguración radical, en el cual muchos de los poblados habitados a lo largo de casi un milenio se abandonan rápidamente. Esta tesis apunta a la profundización del conocimiento de la alfarería producida durante ambos momentos, a partir de la comprensión de las estrategias tecnológicas cerámicas implementadas por los grupos humanos que habitaron el sector denominado El Sunchal en el valle de Anfama (Dto. Tafí Viejo, Tucumán, Argentina).

El trabajo se inserta dentro de un proceso de sedimentación disciplinar, ya establecido, de estudios alfareros que, sin embargo, no presenta casi antecedentes para el área de estudio. Hasta el inicio de las campañas arqueológicas realizadas por nuestro equipo en el año 2014, Anfama solo contaba con dos breves menciones realizadas por Quiroga (1899) y Cremonte (1996). Con lo cual, gran parte de la valía de este aporte radica en el relativo desconocimiento que hay, hasta el momento, sobre la arqueología del valle. Esto ocurre pese a la creciente necesidad de generar análisis y datos empíricos en sectores que permitan perfeccionar y afinar los abordajes desarrollados para casos de transición entre

\footnotetext{
${ }^{1}$ Trabajo Final de Licenciatura en Historia (Facultad de Filosofía y Humanidades, Universidad Nacional de Córdoba) dirigido por el Dr. Julián Salazar (UNC y CONICET). Financiemiento: Beca de iniciación a las vocaciones científicas Consejo Interuniversitario Nacional (CIN). Las tareas de campo del Equipo de Arqueología del Sur de las Cumbres Calchaquíes (EASCC) fueron financiadas parcialmente por Toyota Foundation, National Geographic Society, Fondo para la Investigación Científica y Tecnológica (FONCyT), Secretaría de Políticas Universitarias (SPU), y Secretaría de Ciencia y Técnica de la Universidad Nacional de Córdoba (SECyT - UNC). El trabajo fue defendido el 20/03/2019, actuando como tribunal Julián Salazar (UNC y CONICET); Mariana Fabra (UNC y CONICET) y María Gabriela Srur (UNC y CONICET). Calificación obtenida: 10 (Diez)
}

Anuario de la Escuela de Historia Virtual - Año 10 - N 16 - 2019: pp. 153-157. ISSN 1853-7049 
el área valliserrana y de selvas orientales. Por otra parte, el requerimiento de los actuales comuneros diaguitas de Anfama de recuperar parte de su historia ancestral a través de la Arqueología, y el desarrollo de conocimiento original tendiente a recuperar la historia de las poblaciones originarias de nuestro país, se constituyen también como los fundamentos sociales del trabajo.

La ausencia de trabajos locales específicos conllevó la necesidad de indagar los antecedentes ceramológicos regionales, en los que hubo una serie de interrogantes recurrentes. En primer lugar, los exhaustivos trabajos de Cremonte (1996) en La Ciénega fueron el referente espacialmente más cercano de análisis cerámicos similares a los que aquí se desarrollan. Esta autora plantea la idea de una tradición cerámica de larga duración durante el primer milenio, con lo cual una de las expectativas principales era determinar si el patrón de continuidad temporal también se cumplía en el caso de El Sunchal. A su vez, la presencia de una tradición manufacturera estable durante casi mil años generaba fricciones con el modelo de la Arqueología de la práctica, que es utilizado como parte del marco teórico, con lo cual fue necesario indagar sobre las continuidades y/o discontinuidades prácticas en las distintas fases de las trayectorias de vida y/o de cadenas operativas aquí consideradas.

Durante el desarrollo de la tesis surgió una segunda problemática, relacionada al uso de categorías culturales y a su dificultad de aplicación. Anfama se encuentra geográficamente en un espacio lindante entre lo que se consideró habitualmente desde la Arqueología como "culturas Tafí y Candelaria" (Heredia, 1970). Por lo tanto, un paso lógico era determinar si la cerámica de El Sunchal correspondía a una u otra esfera de influencia. Sin embargo, al tratar de encasillar la cerámica en alguna categoría cultural, se observó la presencia de ambigüedades y/o elementos que se solapaban entre ambas. Ello volvió necesaria la realización de una revisión crítica de este tipo categorizaciones.

El abordaje teórico-metodológico de las problemáticas desarrolladas se basó en la utilización del modelo de trayectorias de vida de los objetos, desarrollado originalmente por Schiffer (1972), el cual es profundizado a partir del concepto de cadenas operativas (García Roselló, 2009), y complementado con herramientas analíticas provenientes de la Teoría Social (Bourdieu, 2007). La presencia en El Sunchal de, al menos, dos fases de ocupación, temporalmente diacrónicas y espacialmente superpuestas, permitió la utilización de la comparación como principal eje de la tesis.

La primera ocupación, datada radiocarbónicamente entre 1900-1600 AP, ha sido identificada en una vivienda de arquitectura similar a la de otras ocupaciones sincrónicas del valle de Tafí y La Ciénega -consta de un gran patio central circular al que se adosan pequeñas habitaciones también circulares-. ${ }^{2}$ Allí, se excavó la totalidad de los relictos de uno de los recintos adosados $\left(6,25 \mathrm{~m}^{2}\right)$, y se analizaron los 688 fragmentos cerámicos recuperados del piso de ocupación, denominado piso A.

Los muros de la estructura "temprana" analizada han sido destruidos parcialmente en una segunda fase de ocupación del sector, que está datada radiocarbónicamente en 1100 AP. En ese momento, se constituye un nuevo recinto, el cual, arquitectónicamente se manifiesta con una construcción de forma semi-rectangular de mayores dimensiones que la precedente. Allí, se excavó parcialmente la ocupación $\left(8 \mathrm{~m}^{2}\right)$, y se analizaron 2286 fragmentos cerámicos del piso del recinto, denominado piso B.

${ }^{2}$ Cf. Berberián y Nielsen (1988) y Cremonte (1996), entre otros.

Anuario de la Escuela de Historia Virtual - Año 10 - N 16 - 2019: pp. 153-157. ISSN 1853-7049 
Sintéticamente, la tesis desarrolla dos ángulos complementarios. Por un lado, indaga las prácticas alfareras en El Sunchal durante el primer milenio de la Era, lo cual puede ser considerado como el aporte empírico del trabajo. Y, por otro lado, se discute en función de los resultados obtenidos la idea de tradición tal como se ha planteado para la región, lo cual puede ser considerado como la contribución teórico-metodológica.

Las metodologías utilizadas para operativizar nuestras hipótesis e interrogantes de investigación fueron: experimentación arqueológica, observación macroscópica, análisis petrográficos y difracción de rayos X. Estas herramientas posibilitaron indagar potenciales fuentes de materias primas, caracterizar estilísticamente los conjuntos cerámicos, identificar los minerales utilizados como antiplásticos, determinar decisiones de elaboración de las clases de pastas, y comparar arcillas arqueológicas con algunas provenientes de distintas vetas identificadas en el valle.

La "arquitectura" de la tesis se ha estructurado en nueve capítulos que, en conjunto, buscan dar cuenta de las inquietudes planteadas en estos párrafos introductorios. El primer capítulo es la introducción a la tesis, en el cual se sintetizan, al igual que aquí, los principales objetivos y elementos teórico metodológicos del trabajo.

Los capítulos dos y tres, por su parte, ofician como introductores al contexto geográfico y académico. El primero de ellos, describe distintos aspectos generales de Anfama. Se presenta brevemente su ubicación espacial, las relaciones arqueológicas del primer milenio de la Era intra e intervalles, y las condiciones climáticas, hidrográficas, geológicas, fitológicas y zoológicas del sector. Luego, en el capítulo tres se abordan los distintos pilares académicos sobre los cuales se erige y con los cuales se discute este en este aporte. Se recuperan los trabajos previos específicos para el valle de Anfama, los desarrollados para el primer milenio en los piedemontes y yungas tucumanos, así como también las distintas líneas teóricas utilizadas para interpretar la cerámica regional.

En el capítulo cuatro se fundamenta el bagaje teórico a partir del desarrollo de los conceptos centrales: trayectorias de vida, cadenas operativas y habitus. También se plantean los problemas interpretativos con los cuales se discute a partir del análisis cerámico y los conceptos propuestos. En el capítulo cinco, por su parte, se ahonda en el sector bajo estudio, partiendo del detalle de las distintas excavaciones realizadas en El Sunchal, de la arquitectura observada, de la secuencia estratigráfica identificada, así como también de la estrategia de construcción de la muestra utilizada.

En el capítulo seis se aborda la primera etapa de las trayectorias de vida cerámicas, la obtención de materias primas, y sus distintas sub-fases dentro de cadenas operativas: traslado hacia las fuentes, identificación y extracción de los materiales. Para ello, en un primer apartado, se desarrollan los resultados obtenidos a partir de aproximaciones experimentales y, en segundo, de los que brindaron los análisis petrográficos y de difracción de rayos $\mathrm{X}$ en los ceramios.

En el capítulo siete se considera la segunda etapa de las trayectorias de vida, la manufactura, así como distintas sub-etapas operativas: preparación de pastas, modelado, acabados de superficie, decoraciones y cocción. Para ello, se utilizaron análisis texturales de los ceramios y se clasificó macroscópicamente a las muestras.

En el capítulo ocho se articulan los resultados obtenidos a lo largo de esta tesis con los interrogantes esbozados en este capítulo introductorio. Se hace hincapié en la integración de la propuesta teórico-metodológica con las prácticas alfareras del primer milenio en El Sunchal y, también, en las discusiones propuestas sobre el concepto de tradición alfarera y de las categorías Tafí y Candelaria.

Anuario de la Escuela de Historia Virtual - Año 10 - Nº 16 - 2019: pp. 153-157. ISSN 1853-7049 
En el capítulo nueve, finalmente, se realiza un cierre a modo de síntesis final con las conclusiones principales que se desprenden del desarrollo de esta investigación, delineando algunos nuevos interrogantes que se originaron a la luz de los resultados obtenidos y diferentes perspectivas que se podrían implementar en el futuro a fin de resolverlos.

Los resultados obtenidos permitieron observar, en primer lugar, un marco de relativa estabilidad tecno-estilística, pero con variaciones temporales a escala microscópica (y algunas a nivel macroscópico). Al respecto, las observaciones microscópicas de cortes delgados confirmaron la presencia de minerales correspondientes con arenas de origen local. Las inclusiones del piso A se muestran más homogéneas composicionalmente que en el B. Esto podría implicar la presencia de un área relativamente estable de obtención de arenas para el primer momento y una mayor variabilidad para la segunda fase de ocupación. La aparición de nuevas clases de pastas para el piso B también podría ser una explicación plausible para esta variación, en tanto podría tratarse de elecciones intencionales en busca de determinados efectos físico-tecnológicos.

En adición, los análisis de DRX realizados para comparar fragmentos arqueológicos con experimentales, mostraron un elevado grado de homogeneidad de los componentes de algunas arcillas locales en relación a tiestos de ambos pisos de ocupación, lo cual permitiría plantear con un elevado grado de certeza la proveniencia local de las arcillas utilizadas.

En relación a la caracterización textural, se constató ampliación de clases de pastas utilizadas simultáneamente en el piso B (12) con respecto al piso A (7). A su vez, algunas continuaron siendo utilizadas en ambos momentos (4), lo cual marcaría una ampliación de elecciones técnicas para $B$ en un marco de continuidad de determinado savoir faire a la hora de elaborar las pastas. También se identificó la presencia de distribuciones bimodales en las pastas finas del piso de ocupación A y de unimodales (sin agregado antrópico de antiplásticos) en el $\mathrm{B}$, lo cual implicaría una variante técnica diacrónica, que sería consistente con una mayor diferenciación al momento de realizar pastas finas y gruesas hacia 900 d.C.

La identificación de morfologías a partir de rasgos diagnósticos fue posible recuperando formas utilizadas en ambos pisos de ocupación. Las mismas dieron cuenta de vasijas asignables a usos cotidianos como almacenaje, cocción y consumo de alimentos, cuya tendencia apunta a la continuidad morfológica, aunque se detectan también algunas formas novedosas en el piso B. En acabados de superficie y decoraciones, se observó la continuidad de la preponderancia de alisados y de baños rojos, incisiones geométricas y aplicaciones al pastillaje en una muy baja proporción. Sin embargo, en el piso B, destaca la aparición de tiestos marleados sin que los mismos se hayan observado para el A.

Sintéticamente, a partir de los abordajes teóricos-metodológicos propuestos, se recuperaron aspectos de las cadenas operativas alfareras y de las trayectorias de vida cerámicas, los cuales permitieron reconstruir uno de los interrogantes centrales del trabajo, es decir, identificar las distintas estrategias prácticas alfareras en El Sunchal durante el primer milenio. Se consideró que la adopción de estrategias tecnológico-alfareras determinadas, que fueron reproducidas a lo largo del tiempo en un sistema de disposiciones mentales y prácticas duraderas, transferibles, responde a especificidades de la organización social (Bourdieu, 2007). Y también se concluyó que las variaciones en la tecnología permiten pensar en reactualizaciones del habitus tecnológico, el cual no deja de ser un aspecto dinámico en la praxis.

Anuario de la Escuela de Historia Virtual - Año 10 - Nº 16 - 2019: pp. 153-157. ISSN 1853-7049 
En segundo lugar, los parámetros morfoestilísticos de las vasijas de El Sunchal se integran dentro de los estándares habituales de las piezas de la región sudcalchaquí para el primer milenio, lo cual nos permite integrarlas dentro de una tradición regional (que no se adecúa a las distinciones clásicas entre "Tafi" y "Candelaria"). Sin embargo, esto no implica que los modos de hacer hayan sido similares en toda esa extensión de territorio y tiempo.

\section{Referencias bibliográficas}

Berberián, E. y A. Nielsen (1988). Sistemas de Asentamiento Prehispánicos en el Valle de Tafí. En E. Berberián (Ed.), Sistemas de Asentamiento Prehispánicos en el Valle de Tafí (pp. 21-51). Córdoba: Editorial Comechingonia.

Bourdieu, P. (2007). El sentido práctico. Buenos Aires: Siglo XXI editores.

Cremonte, M. B. (1996). Investigaciones arqueológicas en la Quebrada de La Ciénaga (Dpto. Tafí, Tucumán). (Tesis de Doctorado). Universidad Nacional de La Plata: La Plata.

García Roselló, J. (2009). Cadena operativa, forma, función y materias primas. Un aporte a través de la producción cerámica del centro de Chile. Relaciones de la SAA, 34, 123148.

Heredia, O. (1970). Investigaciones arqueológicas en el sector Meridional de la subárea de las Selvas Occidentales. (Tesis de Doctorado). Universidad Nacional de Córdoba: Córdoba.

Quiroga, A. (1899). Ruinas de Anfama. El pueblo prehistórico de La Ciénega. Boletín del Instituto geográfico Argentino, 20, 95-123.

Schiffer, M. (1972). Archaeological context and systemic context. American Antiquity, 2, 156-165.

Para citar este resumen:

Franco, Francisco (2019). Resumen de Tesis: “La práctica alfarera durante el primer milenio de la Era en El Sunchal, Anfama (Dto. Tafí Viejo, Tucumán, Rep. Argentina). Trayectorias de vida, cadenas operativas y ¿tradición?". Anuario de la Escuela de Historia Virtual, 16, 153-157. 